\title{
Gringo viejo: la novela como ombligo
}

Guillermo SHERIDAN

Centro de Estudios Literarios

Instituto de Investigaciones Filológicas

Mexico was my identity yet I lacked an identity Carlos Fuentes, "How I started to write"

Gringo viejo, novela publicada en $1985,{ }^{1}$ concentra todos los ingredientes de la discusión sobre "la identidad mexicana en crisis" con que tanto se ha atareado la narrativa de Carlos Fuentes. La novela fue escrita casi al mismo tiempo en que Fuentes publicó en inglés (nunca lo hizo en castellano) su ensayo autobiográfico "How I started to write" (1988). En ese ensayo, Fuentes discurre sobre su identidad dividida entre México, "el país de mi padre" — país pobre, humillado, derrotado- y los victoriosos Estados Unidos donde creció. En ese mismo ensayo declara: "Había aprendido a imaginar a México antes de conocerlo". Sospecho que esta aseveración se encuentra en el meollo de la manera metódica con que el novelista se ha atareado en discutir sus ideas sobre la identidad mexicana. Gringo viejo es un reflejo novelesco de ese ensayo autobiográfico, explota idénticos esquemas de la identidad mexicana y termina por ser la puesta en escena de una paradoja íntima y personal que Fuentes presenta como un choque entre culturas. La idea suele ser la misma: se trata de una identidad quebradiza, titubeante y problemática. La novedad de esta novela en relación con

\footnotetext{
${ }^{1}$ Fondo de Cultura Económica. La traducción al inglés, The Old Gringo, fue publicada por Farrar Strauss \& Giroux en 1986; al francés, Le vieux Gringo por Gallimard en 1985.
} 
otras en las que la crisis de identidad también es tema, es que Gringo viejo decora el asunto con algunos enfoques temáticos y algunos procedimientos estilísticos en la moda académica del momento en que fue escrita. Ha pasado de ser una "identidad mexicana en crisis" a la manera freudiana o existencialista de La región más transparente, a una "identidad mexicana en crisis" a la manera bajtiniana.

Parecería que Fuentes ha creado una pequeña industria que satisface por sí sola — aunque abundan los que siguen sus pasos - la demanda de una narrativa mexicana que, como primera condición, aporte material propicio a la discusión académica sobre la historia, la naturaleza y las vicisitudes de esa identidad. Gringo viejo es el producto más patente de esa industria. El enfrentamiento de los personajes "gringos" con los mexicanos, los lleva a lanzarse mutuamente sus respectivas visiones del mundo de un modo tan extremoso que terminan como actores de sus respectivas identidades. El dilema no deja de ilustrar la ordalía de un escritor que, por su historia personal, vive en carne propia ese enfrentamiento y guarda hacia su mixto origen una contradictoria economía de amor-odio. Parecería que en Gringo viejo Fuentes desea transmitir la experiencia sentimental de esa contradicción a sus lectores, tanto gringos como mexicanos, pero no entenderla: el resultado es casi una caricatura. Los personajes de uno y otro lado de la frontera no padecen sus respectivas identidades, las blanden; no son hombres y mujeres verosímiles, sino depositarios y actores de todos los esquemas tradicionalmente aceptados sobre las peculiaridades culturales de mexicanos o estadounidenses; no se sostienen sobre sus propios pies, sino sobre sus pies de página: más que hombres y mujeres, son excepciones de hombres y mujeres.

La pregunta fundacional del independiente siglo XIX, “¿qué es lo mexicano?” se reformuló con fuerza en el México posterior a la revolución. Una revolución que dejó como saldo la concisa y aparentemente obvia declaración de Gómez Morín, "existen México y los mexicanos" y la tácita tarea cultural de definir en qué consistían uno y los otros. Esta tarea produjo en México respuestas sumamente interesantes en los campos de la historia, la filosofía, la arqueología y la antropología que continúan siendo criticadas y enriquecidas por estudiosos serios y profesionales. Pero como la revolución se institucionalizó en un Estado ávido de legitimación, propició sobre todo un conjunto de propuestas ideológicas que, en materia de arte y literatura, naufra- 
garon con frecuencia en las estrecheces del nacionalismo. Ese nacionalismo aportó una serie de esquemas estéticos e ideológicos que nutrieron la representación que el país hizo de sí mismo y que, desde luego, exportó abundantemente al intenso mercado del sentimentalismo internacional durante las décadas de los veinte y los treinta. ${ }^{2}$ Esos esquemas perviven y reviven cíclicamente desde entonces, sobre todo en los últimos años en que se han convertido en una suerte de horizonte contestatario de los movimientos anti-neoliberales en México, y, desde luego, en la cultura chicana.

Pero ¿cuáles son esos esquemas? Gringo viejo, me parece, hace las veces de un vademécum en tanto que supone que sigue siendo expresión de la identidad mexicana profunda. La novela permite cercar esa identidad en tanto que es uno de los productos más acabados de su actual vulgarización. Las respuestas propiciadas por el Estado a la pregunta "qué es lo mexicano" casi siempre estuvieron infectadas por necesidades inmediatas de tipo político o propagandístico como se mira en el apogeo nacionalista de la década de los treintas y, como apunta puntualmente Carlos Monsiváis (1976), tuvieron al Estado como su beneficiario principal. Las artes colaboraron a reducir la variedad cultural del país (que la misma revolución había hecho visible y actual) a una serie de representaciones estereotipadas y parciales que preservan, desde entonces, el sólido monopolio de la "identidad mexicana". Este monopolio tiende a prevalecer en el mercado sentimental foráneo, incluido el académico que, usurpando el papel antes reservado al Estado, suele imponer desde entonces una tenaz demanda de arte o literatura neo-nacionalista, o posmo-nacionalista.

No puede ignorarse que la secular simpatía occidental por México, y el fervor con el que esa simpatía se pregunta también "qué es lo mexicano", le ha otorgado a la cultura mexicana una enorme simpatía, pero también le ha cobrado los réditos de la simplificación, de una estereotipificación estrecha y estricta. La simpatía se hallaba justificada por varias razones: las impactantes expectativas políticas y sociales engendradas por la revolución de 1910; el afecto depositado por "occidente" en el sustrato indígena del país y en su espectacular pasado histórico y artístico; la vecindad física con los Estados Unidos y sus culpas históricas, sumadas a las de los ingleses y franceses luego del

${ }^{2}$ Me extiendo sobre este asunto en Sheridan 1998. 
martirologio español y las guerras de intervención. Estas razones llevaron a la modernidad a hacer de México otro Oriente, otra África, otra otredad contra la cual las culturas dominantes disfrutan delimitarse y desde la cual, como escribió famosamente Jorge Cuesta (1994) en la década de los treinta, Europa disfruta ejerciendo la crítica de Europa. Las acciones de "lo mexicano" han estado desde entonces a la alza en el mercado de valores de la buena conciencia moderna, y Carlos Fuentes, tan mexicano y a la vez tan cosmopolita, inversionista exitoso, parece interesado en que no cesen de fluir tales réditos. Gringo viejo, que hasta fue traducida al hollywoodense ${ }^{3}$ ha sido su inversión más notable.

Se impone recordar brevemente el argumento de la novela. Ambrose Bierce, gringo viejo, escritor y periodista escéptico y cínico, empleado de Randolph Hearst, decide ir a México en pos de una eutanasia, de ser posible a manos del legendario mexican bandidou Pancho Villa. Bierce es un sofisticado representante nietzscheano de la fatiga histórica. En Chihuahua conoce al general revolucionario Tomás Arroyo —un bárbaro autorizado, un bon sauvage muy malo- dedicado a elaborar algunas escaramuzas revolucionarias con objeto de reivindicar el derecho de su pueblo a unas tierras ancestrales usurpadas por el malvado hacendado Miranda. En esa hacienda abandonada ya no hay nadie, sólo Harriet Winslow, una metodista Gibson Girl originaria de Washington, D. C., contratada para enseñar inglés a los hijos del hacendado, una pura y puritana representante de la democracia y de la moralidad fundacional de los EUA. Cada uno de los protagonistas tiene sus motivaciones secretas: el gringo viejo busca una última oportunidad vital que cancele su deseo de morir, y que resultará ser el amor que le nace por miss Harriet; el general Arroyo quiere recuperar las tierras, pero no tanto por justicia, sino porque desea vengarse del hacendado, de quien es hijo bastardo, para de esa manera subrayar el carácter endogámico de la reyerta civil. Harriet Winslow está en México porque su padre las abandonó a ella y a su madre después de la guerra del 98 (cuando opta por cambiarlas por una negra sobresaliente que ha conocido en Cuba) y no tarda en adoptar como substituto paterno al gringo viejo. El general Arroyo permite al gringo combatir a su lado, pero hace creer a Harriet que va a matarlo si ella no inicia con él un sabroso comercio erótico. Harriet decide aceptar el trato y entrega

\footnotetext{
${ }^{3}$ La película (1989) fue estelarizada por Gregory Peck y Jane Fonda.
} 
espectacularmente su virtud al generalote, lo que enfurece al gringo viejo que, perdida su oportunidad de amar a Harriet, se cobra una rara venganza: quemar los papeles ancestrales con que el rey de España cedía las tierras al pueblo. El general Arroyo asesina entonces al gringo viejo - que es lo que éste deseaba- y Harriet lo abomina. En un final de tragedia renacentista, aparece entonces el príncipe que hace justicia. Sólo que no es príncipe, sino Pancho Villa, famous mexican bandidou, inexplicablemente vestido de torero (en uno de los detalles más extravagantes de la novela). Villa enfrenta a los periodistas gringos - entre ellos está Raoul Walsh- que denuncian ante él que una tal miss Harriet Winslow está acusando a un general villista de haber matado a su padre. Villa ordena a Arroyo que desentierre el cadáver del gringo viejo y ordena que lo fusilen para presentarlo a la prensa como víctima de un escuadrón de fusilamiento de las tropas federales. Luego, ordena fusilar también al general Arroyo. La novela termina con Harriet que se regresa a Washington para enterrar al gringo viejo/padre sustituto en el cementerio de Arlington.

La trama es delirante, plagada de situaciones no por predecibles cercanas a la realidad. Es inverosímil, por ejemplo, que la motivación del general Arroyo sea reivindicar la posesión de la tierra, toda vez que en la revolución del norte no hubo ni reivindicaciones "ni agravios coloniales, ni conflictos entre haciendas y comunidades", como ha señalado el historiador Enrique Krauze (1988), a diferencia de la revolución de Zapata, en el sur. Del clásico libro de John Womack sobre la revolución zapatista, Fuentes toma la escena en la que los viejos indígenas entregan a Zapata los papeles del rey de España y la adapta al improbable indio norteño Arroyo. Como es sabido, hubo varias revoluciones de características muy diferentes en lo político y muy distintas en lo cultural: en el norte una, otra en el sur, una más en el sureste y otra muy diferente en el occidente, la guerra cristera, la más prolongada. Fuentes pone el sur en el norte con la misma facilidad que subsume las variedades de la identidad en un solo paquete, que es como ubicar la batalla de Wounded Knee en Wall Street. Del gran libro de Martín Luis Guzmán, Memorias de Pancho Villa, Fuentes toma la historia de la doble ejecución del inglés Benton y se la expropia para Bierce; Villa "era el gran aliado de los gringos antes de que Wilson reconociera a Carranza” (1985) y ni de chiste se le hubiera ocurrido en ese momento la famosa incursión a Columbus. ¿Y qué decir de los 
amores del potente mexicano Cipriano y la ingenua gringuita Kate, en vivo y en directo desde The Plumed Serpent de D. H. Lawrence? En otro nivel, las discordancias no son menos estentóreas: Harriet viaja de Washington a Chihuahua por la inesperada ruta de Veracruz (que es como ir de Los Angeles a Vancouver por Puerto Rico); un hacendado del norte de esa época les hubiera enseñado francés a sus hijos, no inglés; los mexicanos de Chihuahua no comen ni beben lo que Fuentes dice, ni les dan a las plantas del desierto los nombres que dice el narrador, ni tienen iglesias barrocas ni las mitologías religiosas que se les adjudican. Pero si señalo estos detalles es porque afirman la naturaleza fabular del relato: no se trata tanto de mostrar como de demostrar. Fuentes, que repite ritualmente su fidelidad a Balzac, termina haciendo lo que John Michener: su objetivo es una fábula sobre la vecindad de lo distinto, y lo distinto es un criterio tan amplio que México logra, en la novela, ser distinto hasta de sí mismo.

Nos enfrentamos, pues, a una novela de doble nacionalidad, o fronteriza (por no decir "chicana") cuyo género es igual de ambiguo en tanto que es una novela de la revolución (desde el punto de vista mexicano) y una novela de aventuras en las colonias (desde el punto de vista extranjero). Desde una óptica mexicana, Gringo viejo pertenece a la variante moderna de la vieja novela de la revolución, es decir: identifica al movimiento armado y a sus secuelas — como se hizo durante buena parte de la narrativa mexicana de la primera mitad del siglo- , como escenario de la identidad, resumen de su pasado y augurio de su futuro; como la representación político-social de una crisis identitaria que cifra a la vez lo histórico y lo mítico. Desde el punto de vista foráneo, Gringo viejo pertenece al subgénero de la novela de viaje que consiste en colocar a un "occidental" en medio de una aventura política periférica, al modo de Michel Strogoff de Verne o Fortune carrée de Joseph Kessel. Incluso podría proponerse que Gringo viejo pertenece al sub-subgénero que podría llamarse "extranjeros en la revolución mexicana” que va de Bruno Traven a J. M. Le Clézio, pasando por John Dos Passos, Graham Greene y Katherine Anne Porter, y cuya premisa consiste en enfrentar la identidad europea a la mexicana y observar cómo la del visitante se precipita ante el reactivo de la aborigen. En este sentido, Gringo viejo juega a ser una respuesta interior a la interrogante mexicana sobre su identidad, y, al mismo tiempo, un servicio a la interrogante extranjera. 
Creo que en ambos casos la novela es un éxito, es decir, un fracaso: traiciona el lado mexicano por simple, por replantear sin ningún tipo de ironía, acríticamente, los excesos de la ideología nacionalista de los mexicanos años treintas, para la que la identidad y los "valores nacionales" debían ser decretados y no, como lo sostuvieron los escritores y pensadores no nacionalistas, buscados. ${ }^{4} \mathrm{El}$ resultado fue un nacionalismo "elemental, resentido y retórico que excluyó cualquier otro valor", como señala Krauze (25). Ajustándose a los modales de ese nacionalismo, Fuentes somete a lo indígena la complejidad de esa identidad mexicana variada y plural que la revolución puso al descubierto, $y$ propone al indio, como lo hizo el nacionalismo, como beneficiario de la fuerza simbólica del Estado revolucionario, en tanto que lo considera depósito de la identidad más antigua y legítima de la nación, amén de la más afrentada.

Por otro lado, Gringo viejo satisface con creces al lector foráneo y, en especial, su arraigado impulso por sentimentalizar la romántica necesidad del bon sauvage, el compulsivo ejercicio de hacer digerible al otro nulificando su interlocución a fuerza de clisés, mostrándolo no como es, sino como lo que se espera que sea y, en suma, practicando lo que Guillermo Merquior llamaba "el síndrome de Waldo Frank", es decir: "la beata, acrítica aceptación del retrato latinoamericano como cultura irracional, pintado por el irracionalismo barato de los renegados culturales de la modernidad" (66). En este sentido, Gringo viejo, como producto arquetípico de este sentimentalismo, y como fabulación de la identidad, recicla propuestas de varios orígenes. Por un lado, los elementos deterministas obligados de la representación identitaria heredados de la tradición europea (de "l'état brut" de Buffon al "continente sin historia" de Hegel, que Antonello Gerbi ha descrito en su clásico La disputa del Nuevo Mundo) y, por el otro, el corpus de respuestas sobre "lo mexicano" que, desde y ante lo europeo, fueron elaborados en México a partir de la revolución institucionalizada, y que se esmeraron en proponer interpretaciones de "lo mexicano" desde una amplia variedad de ópticas y métodos, como los "psicoanálisis" culturales de Samuel Ramos en El perfil del hombre y la cultura en

\footnotetext{
${ }^{4}$ El lema de Alfonso Reyes era "En busca del alma nacional"; el del nacionalista Ermilo Abreu Gómez era “¡Demos forma al alma nacional!” (Sheridan 1998).
} 
México o de Jorge Portilla en su Fenomenología del relajo, a la interpretación histórica de Edmundo O'Gorman en La invención de América, o a la crítica moral de Octavio Paz en El laberinto de la soledad y otros escritos. ${ }^{5}$ Gringo viejo realiza una extenuante vulgarización de lo que esos pensadores manejaron como hipótesis, como ensayos de interpretación y, en algunos casos (como en el de Vasconcelos) hasta como proyectos políticos, precisamente para rescatar la cultura mexicana del riesgo de los estereotipos. Gringo viejo es un recetario de identidad mexicana adquirido en el mercado de pulgas intelectual de la década de los cincuentas y de su traslado — autorizado por el ánimo pedagogizante que también caracterizó a la cultura "revolucionaria" - a la forma más accesible de la narrativa. Lo que en sus modelos era tentativa y especulación, en la novela de Fuentes es un sistema inerte, no inquisitivo sino sancionado; no como ejercicio crítico, sino como representaciones cerradas, como atavismos inmodificables. Lo que en sus modelos era crítica moral, se convierte en Fuentes en sistema autorreferencial. En un giro inusitado, la crítica al perfil del mexicano, o a su "soledad" histórica, o al "relajo" como alternativa moral, se convierte en un catálogo de virtudes, de rasgos que supuestamente cifran la esencia de una identidad positiva, cuyo alboroto carnavalesco pone en evidencia a los valores "occidentales" como limitaciones o defectos, tal como lo apunta Fuentes en "How I started to write" (6):

An invisible taskmaster called Puritanical Duty shadows my every footstep: I shall not deserve anything unless I work relentlessly for it... Sloth is $\sin .$. No siestas for me... How I came to envy my Latin brethren, unburdoned by the Protestant ethics... ${ }^{6}$

Del mismo modo, Arroyo, como actor de la "identidad mexicana", parecería haber estudiado las Meditaciones sudamericanas del conde von Keyserling y, luego, haberse esmerado en encarnar, orgullosamen-

\footnotetext{
5 Como la idea de la orfandad en "Los hijos de la Malinche"; la muerte en "Todos santos"; la máscara en "Máscaras mexicanas", etcétera, reunidos en Paz 1987.

6 "Un invisible prefecto llamado Deber Puritano vigila cada paso que doy: no mereceré nada si no trabajo arduamente por merecerlo... La pereza es pecado... nada de siestas para mí... ¡Cómo llegué a envidiar a mis hermanos latinos que no cargan la ética protestante!...”
} 
te, el estereotipo de sexualidad desenfrenada, tristeza metafísica y melancolía histórica que marca a los pobladores del continente.

Narrada desde la evocación de Harriet Winslow - que por cierto comparte datos autobiográficos con Fuentes: infancias en Washington, juegos en Meridian Hill- ("How I became a writer" en Fuentes 1988: 3) y, parecería, con una lista temática de ideologemas identitarios extraídos de las lecturas mencionadas arriba, Gringo viejo subraya varios. La ignorancia paradisíaca de los otros en que vivían los mesoamericanos y que la llegada de los españoles convirtió en perenne angustia ante lo otro. La orfandad, sitio hospitalario por excelencia para radicar el conflicto identitario de la conquista a nuestros días pasando por fray Servando, una orfandad que fractura la identidad histórica y la condena a repetir el esquema arquetípico de la conquista en que el padre viola y desaparece, la madre es preñada y degradada y el hijo huérfano/bastardo busca rencorosamente al padre para hacer(se) justicia como en la paradigmática novela de Rulfo, Pedro Páramo. Pero si los personajes de Rulfo son hombres y mujeres que sucede que son mexicanos de cierta zona y cierta época, los de Fuentes son conceptos que procuran ansiosamente probarse, y probar a otros, que son mexicanos arquetípicos. Los personajes de Fuentes están atareados en ser su identidad, más que en poseerla; obligados a militar en su identidad y, por tanto, en su diferencia. Si en Rulfo la revolución es una puesta en escena trágica en sí misma, en Fuentes es celebración ritual de una orfandad compulsiva (que incluye la indiferencia del "padre" extranjero). De ahí en adelante, la novela va agregando todos los ingredientes del guiso identitario que derivan de esa premisa. El momento crítico en que se ubica la novela colabora a la situación: la revolución acelera el tiempo, coloca las vidas en sus límites y relativiza todos los valores. De este modo, la revolución simboliza en el tiempo lo que la frontera en la geografía: una puesta en extremo de los valores de la convivencia.

En momentos se tiene la impresión de que, con algunos procederes a tal grado hechos de lugares comunes y tan asumidamente vulgares, Gringo viejo es una parodia o una narración retro. Ante el estereotipo de las identidades que describe, por ejemplo, juega a distanciarse haciendo a Bierce decir, cuando conoce al general Arroyo, que "todos los lugares comunes del machismo mexicano le iban a ser arrojados a la cabeza”. O cuando, al conocer a la gringa Harriet, se pregunta “¿Cuá- 
les serán sus lugares comunes?” (39). Esto que parecería cautela de Bierce (y de Fuentes), más que ironía garantiza una seguridad narrativa y una certeza ideológica: frente a los lugares comunes de Arroyo, el gringo narrador responde con otros: la identidad mexicana es una cosa tan opaca que Arroyo "tenía que ser desentrañado para ser entendido y darse" (41). Ahora bien, si la novela desea ser ese desentrañamiento que tiene como objeto "entender" al mexicano, el proceso fracasa de entrada, pues lo bueno de la identidad mexicana es que puede, a nombre de su opacidad, ser descartada como objeto de entendimiento para refugiarse cómodamente en el irracionalismo inefable que sólo puede ser "sentido", no pensado. Ahí refugiado, lo único que le queda a la identidad es acumular piedras sobre su tumba, lugares comunes sobre su opacidad. Y es ahí donde Fuentes traiciona sus fuentes: lo que en Paz o Portilla o Ramos es curiosidad y crítica, en Fuentes es una capitulación a la caricatura.

Una caricatura de caricaturas, como la ausencia de nombre (la bastardía histórica): el general Arroyo tiene nombre, pero no es el suyo (su nombre debería ser Miranda, como su padre bastardo); sus amigos, guerrilleros y adelitas, más funciones que personajes, o carecen de nombre o lo esconden en un apodo ("La Garduña") o en atributos ("La mujer cara de luna"). Otra caricatura de tianguis es la fascinación con la muerte: los mexicanos no se pierden un entierro, le dicen a la muerte "La pelona" (15) y se carcajean de ella, dicen frases como "Lo que pasa es que ese hombre nunca ha estado muerto en toda su vida" (26). Este comercio íntimo con la muerte parece compensarse con la posesión de ciertas facultades extra-sensoriales que les permiten leer cosas invisibles: alguien ve llegar al Gringo y anuncia: "Ese hombre vino aquí a morirse" (16), o bien "Trae un dolor en la mirada" (26). El amor a sus líderes, especies de padres putativos, es un atolondramiento del albedrío: “Viva Villa! ¡Todos somos Villa!, gritó riendo” y un atenuante de la orfandad. Otra más: los mexicanos se ríen todo el tiempo, pero con una risa violenta o dolorosa, y a cada rato sueltan "grandes carcajadas amargas" (82); la risa es también parte de la máscara, esa tumba portátil del bastardo; Arroyo tiene una "máscara asiática que no mostró ninguna emoción" (82), o bien: "la miraron con sus máscaras campesinas que no decían ni sí ni no ni te entendemos ni no te entendemos ni tenemos nuestra propia manera de ser" (92). La máscara oculta las emociones, pero también las sustituye en una suerte 
de caracterización animista que adjudica a los personajes mexicanos miradas de mapache, gritos de coyote o cuerpos de lagarto, o bien metáforas morales que comparan, por ejemplo, su aislamiento y su silencio obstinado a los de una tortuga. La naturaleza misma se animaliza: el "cielo mexicano" es "el eterno círculo de zopilotes" (83). Un lugar común que divierte siempre a los norteamericanos es la noción primitiva del tiempo en el lugar común que deja todo para mañana: "Pobrecita; es muy buena gente pero no sabe qué día es mañana", dice un mexicano de Harriet (93); y junto al mañana, la infaltable mexican siesta: cuando la exhausta Harriet sucumbe a una, al despertar se siente "degradada, inmoral, por caer en el sueño a las cuatro de la tarde” (93). Los mexicanos son supersticiosos, no ven a un gringo a caballo, sino "a un diablo blanco y vengador [que] tenía ojos que sólo los tiene Dios en las iglesias". A veces son franca y llanamente estúpidos: cuando una bebé se ahoga, su madre y otras mujeres le hacen hechicerías hasta que Harriet la salva dándole respiración de boca a boca para luego agregar: "yo estoy vacunada y ella no" (97). Siempre se colapsan en un silencio ladino: "Arroyo era un hombre desnudo, hasta cuando andaba vestido. Era un hombre callado, hasta cuando hablaba" (111). Viven sólo para entregarse a su mexican fiesta, para la que ahorran todo el año, a costa de su salud y su precaria economía, con tal de que el aire se convierta en "el hogar de la pólvora y el incienso unidos", entre cuyas volutas revolotean "los niños enmascarados". Son unos seres atrapados por el oprobio de la idólatra iglesia católica, con todo y su altar "centelleante, auto-devorador, excrementicio" (103) que ostenta sus decoraciones de oro mientras el pueblo se muere de hambre. Buenos salvajes que lo único que entienden es lo que sienten: "Entiendo y siento algunas cosas muy hondo, gringuita, muy hondo, porque si no las siento, no tengo manera de entender nada" (107). Los une la familia, que dura más que la muerte: "cuando se muere alguien vienen sus antepasados; si el gringo viejo se muere aquí, no vendrá nadie. Va a ser muy triste" (147). Quizá las familias están tan unidas porque se ha logrado la desaparición machista de la mujer mexicana, que asquea a Harriet cuando ve a las mujeres "perpetuamente temerosas de ser escuchadas por los hombres" (150). Y para terminar, el cantinflismo que garantiza la nacionalidad: "aquí hablamos con circunloquios terribles", etcétera.

Como la mexicana, la identidad gringa es también una ausencia llena de lugares comunes que la novela dispara generosamente por me- 
dio del Gringo: los Estados Unidos son un sitio que ha institucionalizado históricamente la hipocresía, que disfraza en "la parsimonia, el ahorro, la fe, el amor a los padres, el sentido de la responsabilidad" (80). Y el norteamericano es un sujeto que vive asido de una "filosofía desencuadernada que cada uno escucha y aprende en el hogar: la vida es difícil, la vida es fácil, todo saldrá bien, el orden se impondrá, la caridad empieza en casa... fuertes, ahorrativos, sabios, temerosos de Dios, metodistas sobrios, sin altares barrocos" (94). La novela cataloga también las zonas en que las respectivas identidades entran en un conflicto cuya simpleza alegra el ánimo afecto a los contrastes: el gringo aprende a disfrutar "tacos de criadillas con chile serrano y moronga", aleccionado por el general Arroyo para quien la comida gringa está "envuelta en papel y sellada pa' que no la toquen ni las moscas" (32). Además de las culinarias, hay diferencias físicas: las caras de los gringos "nos parecen igualitas, son caras en chino, deslavadas, toditas igualitas" (que agrega el tópico de la sobre-utilización de diminutivos); los ojos del gringo son "ojos de azul profundo, azul acero" mientras que los de Arroyo son "salvajes ojos amarillos" (37). Hay diferencias hasta en la manera de caminar: los mexicanos lo hacen "taconeado, rápido y corto" mientras que los gringos caminan "largo y silencioso" (134). Desde luego, esos contrastes en la apariencia suponen diferencias en la esencia: para Arroyo, la vida es "acostumbrarse a la muerte", mientras que para Harriet "la vida es una cosa y la muerte otra"; si la iglesia mexicana tiene a un Cristo sangrante en su caja de vidrio, donde todavía sangra, come, fornica, evacúa, el Cristo gringo "liberado para siempre de la carne" es "un espíritu impalpable volando en aras de la música" (103). Si los mexicanos disfrazan sus temperamentos excesivos en la fiesta, los gringos son incapaces de "sacar sus verdaderas emociones al aire sin matarlas” (136). Y así sucesivamente. Los personajes terminan así por encarnar y representar sus respectivas idiosincracias, radicalizadas por el continuo contraste a que se ven sometidas en el relato.

La explicación sobre las tribulaciones de la identidad mexicana parece ser resultado de la mezcla incómoda de dos sexualidades disfuncionales (y una sola persona freudiana): la católica sexualidad española representada por el largo camisón con su ojal en el sexo, vigilado por el Sagrado Corazón de Jesús, y la subyugada sexualidad prehispánica. La repetición de la violación ancestral de la conquista se repite en cada 
matrimonio, que se define como "una ceremonia del miedo" en que la novia niña es castigada por el macho en forma de una violación. Es un castigo que la novia merece "por no ser una niña, por traicionarlo con su sangre menstrual”. Como el novio, por su parte, vive su propio miedo a "la chingada" (es decir, a la rajada vaginal), la posibilidad del amor queda cancelada, suplida por una masturbación ad nauseam (152). Porque, naturalmente, el concepto (estudiado por Octavio Paz en El laberinto de la soledad) de "la chingada" - Malinche, puta, La Muerte - cierra la novela en un furioso descargo de Arroyo contra Harriet: "chingada seas gringa y chingada sea La Luna y chingadas sean todas las viejas que no se parecen a mi madre" (184).

La revolución también puede ser el remedio a esa sexualidad atribulada, pues equivale a la fiesta en la que ritualmente todos se despojan de sus máscaras, en la que las bastardías desaparecen y la armonía familiar se restaura en la tierra recobrada, esa madre original. La libertad para el mexicano existiría así sólo vicariamente como rebelión o "relajo”, mas no como empresa política y social. La rebelión restaura el orden original mientras dura, por lo que el único propósito "político" de Arroyo se reduce a recuperar la tierra y a defender la "necia convicción de nunca ser otra cosa que el mismo, viejo, miserable, caótico país" (102). Es decir, una revolución ni siquiera calculada para restaurar el pasado, sino para crear una temporalidad irreal, un orgasmo mudo y ciego en las goteras de la historia.

¿Será porque el sexo es otra máscara? Arroyo y Harriet extreman en la cama sus diferencias culturales, igual que Cipriano y Kate en La serpiente emplumada y muchas otras parejas románticas. La tendencia europea a criticar la propia identidad oponiéndole otra, enigmática y excéntrica, tiende a resolverse en el plano de la sexualidad, pues recicla la convicción romántica de que la civilización debilita la experiencia de lo natural, una "naturalidad" cuyo extremo simbólico es el sexo. Arroyo, por su parte, entiende el sexo como una forma vicaria de dominación, como un ajuste de cuentas cultural, como una venganza histórica con su dosis de resentimiento. En una escena climática, este "garañón elemental" le ordena a Harriet: "Mírame mirándote" (al parecer el general ha leído a Klossowsky) mientras exhibe orgullosamente su cuerpo, que es en sí mismo un manifiesto identitario, un cuerpo/identidad cuya dureza remite a una profundidad telúrica tan honda como su ombligo: 
...duro pecho moreno y su ombligo hondo y su sexo inquieto, nunca en reposo, a medio llenar como la botella de mezcal, como si los largos y duros testículos, semejantes a un par de aguacates peludos, columpiándose pero duros como piedras entre sus esbeltas, lampiñas, lustrosas piernas indias, estuvieran ocupados incesantemente en la tarea de volver a llenar el pene negro, otra vez brilloso, palpitante, coronado por una aureola del vello más negro que ella había visto jamás... (120).

El espectáculo de este pene telúrico obliga a Harriet a recordar al enamorado gringo que tuvo antes que, claro, tenía "un pene dormido como un enano" que ella, metodista al fin, masturbaba gélidamente para que tuviera "pequeños placeres fríos y espasmódicos". Harriet se percata de que Arroyo no es sino "un arroyo fluido y parejo de sexo: eso es lo que su nombre significaba, Brook, Stream. Creek: Tom Creek, Tom Brook...". Pero como hasta en el sexo hay identidades diferenciadas, él la toma con un "pene como espada que podría abrirla en dos"; mas cuando es ella quien lo toma a él, propinándole una felación, él se niega a terminar en su boca, lo que convierte a la antigua Gibson Girl en una mexicana temperamental: “¿qué te pasa, qué te hace ser como eres, chingada verga prieta, qué te hace negarte a la mujer?” (133). Harriet no sólo ha aprendido a hacer la siesta, ahora también conjuga la palabra mágica chingada. Poco a poco, la mexicana que llevaba dentro (sin saberlo) encuentra la salida; sin embargo, su espiritualidad gringa habrá de prevalecer y le impedirá mirarse en su propio, irracional, espejo interior, por lo que regresa a Washington.

El espejo es en esta novela, como en otras de Fuentes, el símbolo por excelencia. La síntesis de estos reencuentros está simbolizada en el salón de baile de la vieja hacienda, que es lo único que el impulsivo general no destruye: está lleno de espejos y es en ellos que cada uno de los protagonistas atisba su verdadera naturaleza, no muy distinta a las de los otros. Los gringos descubren lo que hay en ellos de mexicanos, lo que tienen en común con ese mundo extraño, impulsivo, salvaje, atemporal y ritual. Mientras que el mexicano no entiende otra cosa que su propia necesidad de consumirse en una inmolación maniática, personal, en la gran hoguera de la historia sorda y ciega representada por Pancho Villa. No es azaroso tampoco que los cuerpos de Arroyo y Harriet, durante la cópula, también sean espejos. La frontera misma 
entre Estados Unidos y México, es otro: la mirada que ponemos en los otros, o que los otros ponen en nosotros, nos obliga a reflejarnos ante nosotros mismos. La cópula vengativa del general, que no retribuye la felación de Harriet, quiere naturalmente aportar una alegoría irónica del comercio cultural entre esas identidades desencontradas. En esta novela en la que, entre la fiesta mexicana, todos son en algún momento hijos, hermanos o padres sustitutos de los demás - lo que supongo quiere subrayar la irreductible familiaridad entre los humanos, más allá de sus identidades particulares_, no hay otra alternativa que resolver las contradicciones en la sexualidad o en la corrección política, como la de Harriet cuando, al final de la novela, concluye que "México no es un país perverso. Es sólo un país diferente" (107). O la de Arroyo, que les pide a los gringos que, en caso de irse, "no nos olviden. Pero, sobre todo, sean de los nuestros sin dejar de ser ustedes" (108).

La narrativa sirve para escapar de esas prisiones, no para encerrarnos más en ellas. La corrección política en éste, como en otros casos, no pasa de ser un lugar cómodo y común. Un lugar común lo es porque hospeda la certidumbre y obvia la crítica. ¿Cabe ahí la teoría, la crítica de la identidad? Una identidad nacional es, si acaso, la definición de las averías que esa identidad ha sufrido. Es, en el peor de los casos, una construcción ideológica más o menos condensada social y culturalmente, pero de la que todo individuo es excepción. Y contra esos rasgos identitarios convertidos en lugares comunes es que se inventó la novela, un género que deriva su carácter de su capacidad para explorar lo excepcional, no de confirmar reglas, sean las que sean. En ese sentido, Gringo viejo perpetúa la paradoja de anhelar definir la identidad mexicana, por un lado, y por el otro convertir a los extranjeros en los jueces que deciden si lo logra o no. Hay unas frases que lanza el general en algún momento que me parecen estremecedoras: “Quieren conocer nuestras vidas mejor? Pues tendrán que adivinarlas, porque todavía no somos nadien!”. Reiteran esa subordinación llena de coquetería cultural y de inseguridad tan útil a los negociantes de "identidad": nadie tiene que adivinar nuestra vida; falso que somos nadie. La condición radicaría en reconocer en la identidad mexicana no una excepción, sino un interlocutor libre de las prisiones de la buena conciencia de sus interlocutores. Y también, en no confundir las fértiles preguntas con las respuestas interesadas. 
BiBLIOGRAFÍA

Cuesta, Jorge. "La literatura y el nacionalismo" (1932), en Obras. México: El Equilibrista, 1994.

Fuentes, Carlos. Gringo viejo. México: Fondo de Cultura Económica, 1985.

—. Myself and Others. Nueva York: Farrar Strauss, 1998.

Krause, Enrique. "La comedia mexicana de Carlos Fuentes", en Vuelta 139 (junio de 1988). 15-27.

Merquior, Guillermo. "Gilberto [Freyre] y después", en Vuelta 131 (octubre de 1987). 63-66.

MonsivÁis, Carlos. "La nación de unos cuantos y las esperanzas románticas (notas sobre la historia del término cultura nacional en México)", en En torno a la cultura nacional. México: Secretaría de Educación Pública / Instituto Nacional Indigenista, 1976.

Paz, Octavio. México en la obra de Octavio Paz. I. México: Fondo de Cultura Económica, 1987.

Sheridan, Guillermo. México en 1932: la disputa nacionalista. México: Fondo de Cultura Económica, 1998. 